\title{
CARACTERÍSTICAS FÍSICO-QUÍMICAS E MICROBIOLÓGICAS DO QUEIJO ARTESANAL PRODUZIDO NA MICRORREGIÃO DE MONTES CLAROS - MG
}

\section{Physicochemical and microbiological characteristics of traditional Minas cheese produced in the micro-region of Montes Claros - MG}

\author{
Maximiliano Soares Pinto ${ }^{I^{*}}$, Marcus Welbert Lempk ${ }^{l}$, Carolina Campos Cabrini, \\ Lorena Katheryne Vieira Saraiva ${ }^{l}$, Roberta Ribeiro da Cruz Cangussu ${ }^{l}$, \\ Ana Luisa Ferreira Simões Cunha ${ }^{1}$
}

\section{RESUMO}

A valorização de queijos artesanais é crescente nos últimos anos. Atualmente qualquer município do estado de Minas Gerais pode solicitar o seu credenciamento como região produtora de queijo Minas artesanal. A produção de queijo está presente em todos os municípios da microrregião de Montes Claros e possui valor social inquestionável para a população. Entretanto não há sequer estudos iniciais para que, diante dos resultados, ações possam ser planejadas visando tirar o queijo da informalidade. Este trabalho teve como objetivo caracterizar os aspectos físicoquímicos e microbiológicos do queijo artesanal da microrregião de Montes Claros, MG. As análises microbiológicas feitas foram: coliformes $30^{\circ} \mathrm{C}$, Escherichia coli, Staphylococcus aureus, Salmonella sp e Listeria sp.. E para as análises físicoquímicas foram: $\mathrm{pH}, \mathrm{a}_{\mathrm{w}}$, gordura, umidade, cloretos, nitrogênio total, extensão e profundidade de maturação e cinzas em 18 queijos representados pelos municípios que compõem a microrregião de Montes Claros, MG. Assim como acontecia nas regiões tradicionais no passado, é notória a falta de padronização dos queijos analisados, assim como condições microbiológicas insatisfatórias para consumo. Tornam-se necessárias ações de pesquisa e principalmente extensão para que seja possível a produção de queijos passíveis de serem consumidos.

Palavras-chave: queijo Minas artesanal; segurança alimentar; leite cru.

1 Universidade Federal de Minas Gerais (UFMG), Instituto de Ciências Agrárias, Av. Universitária, 1000, bairro Universitário, 39404-006, Montes Claros, MG, Brasil. Email: maxonze@yahoo.com.br

* Autor para correspondência. 


\begin{abstract}
Artisan cheese appreciation has increased in recent years. Currently, any municipality in the Minas Gerais state, Brazil, can request its accreditation as a region that produce Artisan Minas cheese. Cheese production is present in all the municipalities of the Montes Claros micro-region, in Minas Gerais, and it has an unquestionable social value for the population. Nevertheless, there are not even initial studies so that actions could be planned in order to remove cheese manufacturing from the informality. The aim of this work was to characterize the physic-chemical and microbiological aspects of Artisan cheese from Montes Claros micro-region. It was selected 18 cheeses from the municipalities of that region. The microbiological analyzes were: coliforms $30^{\circ} \mathrm{C}$, Escherichia coli, Staphylococcus aureus, Salmonella sp e Listeria $\mathrm{sp}$. The physic-chemical assays $\mathrm{pH}, \mathrm{A}_{\mathrm{w}}$, fat content, moisture, chlorides, total nitrogen, ashes and extent and depth of maturation were carried out. As was the case of traditional regions in the past, there is a lack of standardization of the analyzed cheese samples, as well as unsatisfactory microbiological conditions for consumption. There is a need of actions regarding research and extension in order to be possible to produce cheeses that can be actually consumed.
\end{abstract}

Keywords: traditional Minas cheese; food safety; raw milk.

\section{INTRODUÇÃO}

A fabricação artesanal de queijos ocupa um importante papel econômico, social e cultural no estado de Minas Gerais. Há mais de 200 anos é fabricado de maneira rústica em pequenas propriedades rurais e esta atividade é responsável pela sustentabilidade das famílias de pequenos produtores (ARAUJO, 2008).

O queijo Minas artesanal foi legalizado pela Lei Estadual $n^{\circ} 14.185$, de 31 de janeiro de 2002 que dispõe sobre o seu processo de produção. A Lei 19.492 de 13 de janeiro de 2011, também passa a tratar que os queijos Minas artesanais confeccionados, conforme a tradição histórica e cultural da área demarcada onde for produzido, receberá uma certificação diferenciada (MINAS GERAIS, 2002; MINAS GERAIS, 2011).

Atualmente Minas Gerais conta com sete regiões reconhecidas como produtoras de queijos artesanais, além das regiões do Serro, Canastra, Cerrado, Araxá e Campo das
Vertentes, em 2014 foram incluídas duas microrregiões, Triangulo Mineiro e Serra do Salitre pelas Portarias $n^{\circ} 1397$ (MINAS GERAIS, 2014a) e nº 1428 (MINAS GERAIS, 2014b) respectivamente.

O norte de Minas Gerais é caracterizado por grande diversidade física, social e econômica possuindo baixos indicadores socioeconômicos. Porém, não significa que não apresente potencialidades a serem exploradas para um desenvolvimento sustentável. As políticas de valorização de produtos locais, regionais ou artesanais têm se tornado ferramenta na implementação de projetos de desenvolvimento em zonas rurais que se encontram menos favorecidas e à margem dos modelos de desenvolvimento agrícola vigentes (COSTA et al. 2010).

A microrregião de Montes Claros é composta por 22 municípios: Brasília de Minas, Campo Azul, Capitão Eneias, Claro dos Poções, Coração de Jesus, Francisco Sá, Glaucilândia, Ibiracatu, Japonvar, Juramento, Lontra, Luislândia, Mirabela, Montes Claros, 
Patis, Ponto Chique, São João da Lagoa, São João da Ponte, São João do Pacuí, Ubaí, Varzelândia e Verdelândia.

A caracterização do perfil físico-químico dos queijos da região do Norte de Minas Gerais, tal como foi feita com os queijos das outras regiões, é um passo importante para que se conheça a realidade dos produtores de queijo desta região. Este trabalho teve como objetivo caracterizar os aspectos físico-químicos e microbiológicos do queijo artesanal da microrregião de Montes Claros, MG.

\section{MATERIAL E MÉTODOS}

O campo amostral de coleta dos queijos foi selecionado de acordo com os 22 municípios que compõem a microrregião de Montes Claros. Desses municípios, 18 foram visitados em função de fácil acesso e disponibilidade da EMATER para a coleta do queijo.

\section{Coleta das amostras}

Foi coletado um queijo pertencente a uma propriedade de cada município visitado que compõe a microrregião de Montes Claros totalizando 18 amostras de queijos artesanais. O transporte até o laboratório foi feito utilizando uma caixa de isopor em temperatura ambiente com o tempo máximo de transporte de 4 horas.

Os queijos foram analisados no dia posterior as suas coletas e possuíam em média oito dias de maturação. Foram retiradas de cada peça de queijo duas cunhas de aproximadamente $200 \mathrm{~g}$ que foram destinadas a análises microbiológicas e análises físicoquímicas. As amostras foram preparadas segundo as técnicas oficiais da Instrução Normativa $\mathrm{n}^{\circ} 68$, de 12 de dezembro de 2006 (BRASIL, 2006).

\section{Análises microbiológicas e físico-químicas}

Para as análises de $S$. aureus foi utilizado o Petrifilm 3M Rapid S. aureus (RSA), da fabricante $3 \mathrm{M}$, de acordo com os procedimentos determinados pelo distribuidor. Para análise de Listeria sp. e Salmonella sp. foram utilizados os kits Reveal, da fabricante Neogen Corporation.

Para a contagem de coliformes $30^{\circ} \mathrm{C}$ e Escherichia coli utilizou-se o Petrifilm Coliform/E.coli, da fabricante $3 \mathrm{M}$, de acordo com os procedimentos determinados pelo distribuidor.

A determinação do $\mathrm{pH}$ do queijo foi feita utilizando-se medidor de $\mathrm{pH}$ modelo Qualxtron model 8010, introduzindo-se o eletrodo na parte interna dos queijos. A determinação da $a_{w}$ foi feita utilizando-se medidor digital Aqualab, modelo série 3TE, utilizando-se porções do queijo.

Para a determinação de gordura, umidade, nitrogênio total e cloretos, foram utilizados os métodos oficiais para as referidas análises, descritos na Instrução Normativa $\mathrm{n}^{\mathrm{o}} 68$, de 12 de dezembro de 2006 (BRASIL, 2006).

Para determinação de cinzas e proteínas foram utilizadas as técnicas de Pereira et al. (2001), em que o nitrogênio não proteico (NNP) foi determinado de acordo com a técnica do ácido tricloroacético. A proteína verdadeira foi determinada subtraindo-se o valor do NNP do nitrogênio total. Após esse cálculo, o resultado obtido foi multiplicado por 6,38 .

A extensão de maturação foi quantificada pela razão (\%) entre o nitrogênio solúvel em $\mathrm{pH}$ 4,6 e o nitrogênio total, enquanto a profundidade de proteólise foi quantificada pela razão (\%) entre o valor do nitrogênio não proteico (NNP) pelo valor do nitrogênio total de cada amostra (POMBO; LIMA, 1989). 


\section{RESULTADOS E DISCUSSÃO}

\section{Parâmetros microbiológicos do queijo ar- tesanal da microrregião de Montes Claros}

De acordo com Decreto ${ }^{\circ} 44.864$, que altera o Regulamento da Lei n. 14.185, de 31 de janeiro de 2002, que fixa os parâmetros físicoquímicos e microbiológicos para queijos Minas artesanais (MINAS GERAIS, 2008), todos os queijos analisados da microrregião de Montes Claros tiveram resultados para coliformes $30^{\circ} \mathrm{C}$ e $S$. aureus superiores aos permitidos pela legislação, no qual seus valores máximos são de 3,70 $\log (\mathrm{UFC} / \mathrm{mL})$ e 3,00 Log (UFC/mL), respectivamente. Para os resultados de E. coli, apenas uma amostra de queijo das propriedades apresentou-se dentro dos valores máximos permitidos pela legislação, que é de 2,70 $\log (\mathrm{UFC} / \mathrm{mL})$ (Tabela 1).
Observa-se na Tabela 2 que se comparando esses resultados com os de outras microrregiões no passado e que hoje estão inseridas no circuito do queijo Minas artesanal, pode-se verificar que eram similares. Atualmente várias unidades produtoras das microrregiões do Serro, Araxá e Canastra são cadastradas no Instituto Mineiro de Agropecuária (IMA) e podem comercializar legalmente os queijos.

Foram detectadas a presença de Salmonella sp. em duas amostras de queijo e nenhuma das amostra apresentou Listeria sp. A alta contaminação verificada no presente estudo indica condições insalubres no local de processamento, manipulação inadequada e condições higiênicas insatisfatórias. Todas elas passíveis de correções desde que ações eficientes sejam adotadas.

A mastite estafilocócica em bovinos é um dos fatores que contribuem para os

Tabela 1 - Parâmetros microbiológicos do queijo artesanal da microrregião de Montes Claros

\begin{tabular}{ccccc}
\hline \multirow{2}{*}{ Grupos Microbianos } & ${ }^{1}$ Média \pm DP & Menor Contagem & Maior Contagem & C.V. \\
\cline { 2 - 5 } & \multicolumn{4}{c}{ Log UFC/g } \\
\hline Coliformes $30^{\circ} \mathrm{C}$ & $5,78 \pm 1,16$ & 3,94 & 7,40 & 0,20 \\
E. coli & $4,65 \pm 1,03$ & 2,60 & 6,70 & 0,22 \\
S. aureus & $6,54 \pm 0,77$ & 5,04 & 7,61 & 0,12 \\
\hline
\end{tabular}

${ }^{1}$ Média \pm Desvio padrão; C.V = Coeficiente de variação.

Tabela 2 - Percentual dos produtores inadequados à legislação em relação aos parâmetros microbiológicos para queijo Minas artesanal em outras regiões de Minas Gerais

\begin{tabular}{ccccc}
\hline \multirow{2}{*}{ Grupos Microbianos } & Montes Claros & Araxá $^{1}$ & Serro $^{2}$ & Canastra $^{3}$ \\
\cline { 2 - 5 } & \multicolumn{3}{c}{$\%$} \\
\hline S. aureus & 100 & 86,49 & 100 & 52,5 \\
Coliformes $30{ }^{\circ} \mathrm{C}$ & 100 & 48,65 & 76,0 & 50,0 \\
E. coli & 94,44 & 37,84 & 31,0 & 45,0 \\
Salmonella sp. & 2,00 & 7,00 & 0 & 0 \\
Listeria sp. & 0 & 0 & 0 & 1 \\
\hline
\end{tabular}

Fontes: ARAÚJO'1, 2008; PINTO² et al., 2004; ORNELAS $^{3}, 2005$. 
resultados posivtivos de $S$. aureus em produtos lácteos provenientes de leite não pasteurizado (LANCETTE; BENNETT, 2001).

Ornelas (2005) concluiu que a qualidade microbiológica dos queijos produzidos na Serra da Canastra estava insatisfatória, sendo $85 \%$ em desacordo com os padrões legais vigentes. Enterotoxinas estafilocócicas, coliformes a $35{ }^{\circ} \mathrm{C}$ e $45^{\circ} \mathrm{C}$ foram detectadas em elevado número de amostras, L. monocytogenes foi isolada de uma amostra e Salmonella sp. não foi observada.

\section{Parâmetros físico-químicos do queijo ar- tesanal da Microrregião de Montes Claros}

Na Tabela 3 são apresentadas as médias dos valores encontrados nas análises das amostras dos produtores de queijo Minas artesanal da microrregião de Montes Claros e na Tabela 4 são mostradas as médias dos parâmetros físico-químicos dos queijos de outras regiões produtoras em Minas Gerais.

$\mathrm{O}$ pH médio encontrado para os queijos artesanais da microrregião de Montes Claros foi de 5,36. Em relação ao $\mathrm{pH}$, não existem valores para esse atributo nos documentos de caracterização do Queijo Minas Artesanal do Serro e de Araxá (APROCAN, 2006; APAQS, 2006). O que se pode ver nos documentos supracitados é um limite inferior e superior de acidez recomendada dos queijos. Entretanto, a acidez em queijo é influenciada por diferentes fatores, além da presença de $\mathrm{H}^{+}$, tornado-a assim um indicador ineficaz para a caracterização. Ainda que cada região esteja livre para produzir queijos com diferentes valores de $\mathrm{pH}$, é importante ressaltar que este atributo em um alimento influencia no crescimento e controle de microrganismos patogênicos. Sabe-se que em alimentos com $\mathrm{pH}$ abaixo de 4,6 praticamente não há crescimento de potenciais patógenos (HOFFMANN, 2001; BAPTISTA; VENÂNCIO, 2003). Uma vez que os queijos apresentam valores de $\mathrm{pH}$ superiores a este limite, tem-se a necessidade de maior rigor em todas as etapas de produção deste alimento. A Tabela 4 apresenta as características físico-químicas de queijos de outras microrregiões produtoras.

Tabela 3 - Estimativa da média, desvio padrão e variância dos parâmetros físico-químicos dos queijos artesanais da microrregião de Montes Claros

\begin{tabular}{ccccc}
\hline Parâmetro & Média $\pm \mathrm{DP}^{1}$ & $\begin{array}{c}\text { Menor } \\
\text { resultado }\end{array}$ & $\begin{array}{c}\text { Maior } \\
\text { resultado }\end{array}$ & C.V $^{2}$ \\
\hline $\mathrm{pH}$ & $5,36 \pm 0,28$ & 4,95 & 5,99 & 0,05 \\
$\mathrm{a}_{\mathrm{w}}$ & $0,97 \pm 0,01$ & 0,95 & 0,99 & 0,01 \\
Gordura (\%) & $26,34 \pm 3,35$ & 21,0 & 34,00 & 0,13 \\
Umidade (\%) & $48,05 \pm 4,26$ & 38,85 & 57,35 & 0,09 \\
Cloretos (\%) & $1,82 \pm 0,71$ & 0,90 & 3,73 & 0,39 \\
Proteína total (\%) & $21,09 \pm 2,96$ & 15,90 & 29,69 & 0,14 \\
Extensão maturação (\%) & $9,88 \pm 2,74$ & 5,80 & 16,99 & 0,28 \\
Profundidade maturação (\%) & $3,85 \pm 2,16$ & 0,60 & 9,69 & 0,56 \\
Cinzas (\%) & $4,05 \pm 0,76$ & 2,76 & 5,70 & 0,19 \\
\hline
\end{tabular}

${ }^{1} \mathrm{DP}=$ Desvio padrão.

${ }^{2} \mathrm{C} . \mathrm{V}=$ Coeficiente de variação $(\%)$. 
Observa-se que os valores de $\mathrm{pH}$ encontrados nos queijos estudados são similares aos do queijo Minas artesanal da Canastra, o que evidencia na região um queijo com menor teor de acidez do que a microrregião do Serro, distante aproximadamente $300 \mathrm{~km}$ da microrregião de Montes Claros.

Assim como o $\mathrm{pH}$, não existe valores fixos de $a_{w}$ para queijos Minas artesanais em nenhum documento de caracterização dos mesmos. Sabe-se, entretanto, que a $a_{w}$ é limitante para o crescimento de bactérias desejáveis e indesejáveis. Os valores de $\mathrm{a}_{\mathrm{w}}$ encontrados nos queijos do presente trabalho não apresentam limitações para o desenvolvimento da acidez por bactérias láticas e a consequente maturação dos queijos. Entretanto propiciam também o crescimento de possíveis patógenos, caso os mesmos estejam presentes nos queijos o que evidencia novamente a necessidade de rigor na produção e fiscalização deste tipo de alimento.

Os principais fatores que influenciam a $\mathrm{a}_{\mathrm{w}}$ em queijos são o teor de umidade, sólidos não gordurosos, teor de cloretos no queijo e a maturação quando ocorre o aumento do nitrogênio solúvel e do nitrogênio não proteico e ácidos graxos livres (DORES, 2007).

Observou-se variação nos teores de umidade dos queijos produzidos nos diferentes municípios. Todavia a variação encontrada neste estudo é menos do que as observadas em queijos de outras microrregiões produtoras (PINTO, et al. 2011; SOBRAL, 2012; TEODORO, 2012). Essa variação pode ser explicada pela falta de padronização no tamanho dos grãos, resultando em queijos com variados teores de umidade. Esse fator é importante, pois quanto menor o grão, menor será o teor de umidade do queijo (PINTO et al. 2004).

O teor médio de cloretos encontrado foi de $1,82 \%$, sendo o menor valor encontrado $0,90 \%$, e o maior 3,73\%. Este resultado está dentro dos teores de cloretos encontrados por Pinto et al. (2004), Araújo (2008) e Resende (2010) em seus trabalhos.

A variação dos teores de sal se explicaria pela falta de padronização na fase do processamento e pelo tipo de salga, no caso salga a seco, em que a quantidade de sal não é medida, além de não ser bem definido o tempo de salga (IDE; BENEDET,

Tabela 4 - Média dos resultados físico-químicos dos queijos artesanais de outras regiões de Minas Gerais

\begin{tabular}{ccccc}
\hline Atributo & Araxá & Serro & Canastra & Montes Claros \\
\hline $\mathrm{pH}$ & 4,856 & 4,751 & 5,343 & 5,36 \\
$\mathrm{a}_{\mathrm{w}}$ & 0,976 & 0,921 & $\mathrm{ND}$ & 0,97 \\
Gordura (\%) & 28,296 & 28,211 & 27,583 & 26,34 \\
Umidade (\%) & 45,056 & 48,221 & 43,493 & 48,05 \\
Cloretos (\%) & 2,066 & 1,621 & 1,953 & 1,82 \\
Proteína total (\%) & 24,406 & 22,401 & 29,904 & 21,09 \\
Extensão maturação & 9,356 & 11,011 & 12,284 & 9,88 \\
Profundidade maturação & 5,436 & 4,621 & 9,474 & 3,85 \\
Cinzas & ND & 3,792 & 4,355 & 4,05 \\
\hline
\end{tabular}

Fonte: ${ }^{1}$ PINTO, 2004; ${ }^{2}$ MACHADO et al., 2004; ${ }^{3}$ RESENDE, 2010; ${ }^{4}$ SILVA, 2007; ${ }^{5}$ VARGAS et al., 1998 ; ${ }^{6}$ ARAÚJO, 2008. ND = Não disponível. 
2001; PINTO et al., 2004; ARAÚJO, 2008). A função do sal no queijo é conferir-lhe o gosto característico, ao mesmo tempo em que realça ou mascara o sabor de outras substâncias. O sal ajuda na dessoragem do queijo, favorecendo a liberação de água livre da massa e exerce ainda importante papel na seleção da microbiota do queijo (FURTADO, 1990).

O resultado encontrado para cinzas foi em torno de $4,05 \%$. Valores próximos aos encontrados por Machado et al.(2004) na região do Serro e por Vargas et al. (1998) na região da Canastra (Tabela 4). Furtado (1990) afirma que o papel das cinzas é de grande importância no que se refere à textura final dos queijos. A massa de queijo é como se fosse um conjunto, em que o cálcio forma a estrutura, atuando como elemento de ligação.

$\mathrm{O}$ teor de gordura encontrada nos queijos artesanais da microrregião de Montes Claros foi de $26,34 \%$, teor mais baixo do que os encontrados nas outras regiões produtoras de queijos artesanais. A região da Canastra apresenta um teor de gordura de $27,58 \%$, sendo o resultado mais próximo encontrado para o queijo da microrregião de Montes Claros.

Segundo o regulamento técnico de identidade e qualidade de queijos (BRASIL, 1996), os queijos artesanais da microrregião de Montes Claros analisados, podem ser enquadrados como queijos semi-gordos, por estarem dentro da faixa de 25 a $49 \%$ de gordu ${ }^{-}$ ra. Assim como estão classificados os queijos do Serro, Canastra e Araxá.

Para as análises de proteínas foi encontrado um resultado médio de $21,09 \%$, valor abaixo dos encontrados nos queijos das regiões do Serro, Canastra e Araxá (Tabela 4). A região do Serro é a que apresenta o resultado mais próximo do encontrado para a microrregião de Montes Claros, apresentando $22,4 \%$ de proteína.

O índice de proteólise ou extensão da maturação é o resultado da ação proteolítica das enzimas do coalho sobre a caseína do queijo (SILVA, 2007). O valor médio encontrado para este parâmetro foi de $9,88 \%$. Valor abaixo dos encontrados nas outras regiões, mas está próximo aos resultados obtidos na região de Araxá. A variação na extensão de maturação pode ser explicada pelo uso indiscriminado de coalho, que pode estar sendo utilizado em quantidade maior ou menor que o indicado pelo fabricante (PINTO, 2004).

A profundidade de maturação determinada para o queijo Minas artesanal da microrregião de Montes Claros foi de 3,85\%, valor muito abaixo dos encontrados nas regiões de Araxá, Serro e Canastra. Esse baixo valor comparado com os das outras regiões, pode ser explicado devido à ausência do "pingo" na tecnologia de fabricação do queijo artesanal da microrregião de Montes Claros, sendo o leite fermentado apenas microbiota endógena do leite. A profundidade de maturação é o resultado da ação proteolítica do fermento lático sobre peptídeos liberados, principalmente pelo coalho, produzindo aminoácidos e compostos de baixo peso molecular. Logo está relacionada com a atividade proteolítica do fermento lático na maturação (SILVA, 2007).

\section{CONCLUSÕES}

A grande variação nos parâmetros físico-químicos demonstra falta de padronização no processo de produção desse queijo, o que dificulta estabelecer um padrão para o queijo artesanal da região.

$\mathrm{Na}$ experimentação foi possível perceber que microbiologicamente o queijo da região de Montes Claros não oferece segurança alimentar aos seus consumidores. 100\% das amostras analisadas apresentaram contagens para $S$. aureus superior ao permitido pela legislação, além de duas amostras evidenciarem a presença de Salmonella sp. 
A contagem de coliformes e E. coli acima da permitida pela legislação demonstra que os produtores não seguem as práticas higiênicas essenciais para produzir o queijo.

Os padrões microbiológicos insatisfatórios, juntamente com a grande variação físico-química apresentada nas amostras analisadas, confirmam serem imprescindíveis melhorias no processo de produção do queijo para aumentar a qualidade do queijo da região.

\section{REFERÊNCIAS}

ARAUJO, T. F. Caracterização e identificação de Enterococcus spp. isolados do fermento endógeno utilizado na fabricação do queijo minas artesanal da região da Canastra, Minas Gerais. 2008. 63 f. Dissertação (Mestrado em Ciência e Tecnologia de Alimentos) - Universidade Federal de Viçosa, Viçosa, 2008.

APAQS. Caracterização do queijo Minas artesanal do Serro. Associação dos Produtores Artesanais do Queijo do Serro, dezembro, 2006.

\section{APROCAN, Caracterização do Queijo} Minas Artesanal da Serra da Canastra. Associação dos Produtores dos Produtores Rurais da Canastra, dezembro, 2006.

BAPTISTA, P.; VENÂNCIO, A. Os perigos para segurança alimentar no processamento de alimentos. 2003. Disponível em: $<$ https:// www.forvisao.pt/files/manual_4.pdf $>$ Acesso em: 15 ago. 2016.

BRASIL. Ministério da Agricultura, Pecuária e Abastecimento. Portaria $n^{\circ} 146$, de 7 de março de 1996. Aprova os regulamentos técnicos de identidade e qualidade dos produtos lácteos. Diário Oficial da República Federativa do Brasil, Brasília, 11 mar. 1996. Seção 1.
BRASIL. Ministério da Agricultura, Pecuária e Abastecimento. Instrução Normativa $n^{\circ}$ 68, de 12 de dezembro de 2006. Oficializa os métodos analíticos oficiais físico-químicos, para controle de leite e produtos lácteos. Diário Oficial da República Federativa do Brasil, Brasília, 14 dez. 2006. Seção 1, p. 8.

COSTA, D. S. M. et al. As potencialidades da região semiárida do norte de Minas Gerais: Análise do Centro de Estudos de Convivência com o Semiárido. In: ENCONTRO NACIONAL DE GEÓGRAFOS, 16, 2010, Porto Alegre. Anais... Porto Alegre: [s.n.], 2010.

DORES, M. T. Implicações do processo de maturação a temperatura ambiente e sob refrigeração do queijo Minas artesanal da Canastra produzido na região de Medeiros, Minas Gerais. 2007. 101 f. Dissertação (Mestrado em Ciência e Tecnologia de Alimentos) - Universidade Federal de Viçosa, Viçosa, 2007.

IDE, L. P. A.; BENEDET, H. D. Contribuição ao conhecimento do queijo Colonial produzido na região Serrana do Estado de Santa Catarina, Brasil. Revista Ciência Agrotécnica, v. 25, n. 6, p. 1351-1358, 2001.

HOFFMANN, F.; L. Fatores limitantes à proliferação de microrganismos em alimentos. Brasil Alimentos, n. 9, p. 23-30, 2001.

FURTADO, M. M. A arte e a ciência do queijo. São Paulo: Editora Globo, 1990, 297 p.

LANCETTE, G. A.; BENNETT, R. W. Staphylococcus aureus and staphylococcal enterotoxins. In: DOWNES, F. P. Compendium of methods for the microbiological examination of foods. Washington: APHA, 2001.

MACHADO, E. C. et al. Características 
físico-químicas e sensoriais do queijo Minas artesanal do Serro, Minas Gerais. Revista Ciência e Tecnologia de Alimentos, v. 24, n. 4, p. 516-521, 2004.

MINAS GERAIS. Decreto 44.864 de 01 de agosto de 2008. Altera o regulamento da lei $\mathrm{n}^{\mathrm{o}} 14.185$, de 31 de janeiro de 2002, que dispõe sobre o processo de produção de Queijo Minas Artesanal. Minas Gerais Diário do Executivo, p. 1, col. 2, 15 ago. 2008.

MINAS GERAIS. Assembléia Legislativa do Estado de Minas Gerais. Lei no 14185 , de 31 de janeiro de 2002. Dispõe sobre o processo de produção do queijo Minas artesanal e da outras providencias. Diário do Executivo e do Legislativo e Publicações de Terceiros, 01. fev. 2002.

MINAS GERAIS. Decreto 19.492 de 13 de janeiro de 2011. Altera o regulamento da lei $\mathrm{n}^{\mathrm{o}} 14.185$, de 31 de janeiro de 2002, que dispõe sobre o processo de produção de Queijo Minas Artesanal. Minas Gerais Diário do Executivo, p. 1, 13 jan. 2011.

MINAS GERAIS. INSTITUTO MINEIRO DE AGROPECUÁRIA. Portaria ${ }^{\circ} 1397$, de 13 de fevereiro de 2014. Identifica a Microrregião do Triângulo Mineiro como produtora de Queijo Minas Artesanal. Secretaria de Agricultura, Pecuária e Abastecimento de Minas Gerais. Belo Horizonte, 2014a. Disponível em: <http:/www.ima.mg.gov.br/ portarias/doc_details/1315-portaria-no-1397de-13-defevereiro-de-2014>. Acesso em: 12 abr. 2016.

\section{MINAS GERAIS. INSTITUTO MINEIRO} DE AGROPECUÁRIA. Portaria $n^{\circ} 1428$, de 29 de agosto de 2014. Identifica a microrregião da Serra do Salitre como produtora do queijo Minas artesanal. Secretaria de Agricultura, Pecuária e Abastecimento de Minas
Gerais. Belo Horizonte, 2014b. Disponível em: <http:/www.ima.mg.gov. br/portarias/ doc_details/1556-portaria-no-1428-de-29de-agosto-de-2014>. Acesso em: 12 abr. 2016

ORNELAS, E. A. Diagnóstico preliminar para caracterização do processo e das condições de fabricação do queijo artesanal da Serra da Canastra - MG. 2005. 65 f. Dissertação (Mestrado em Medicina Veterinária) Escola de Veterinária, Universidade Federal de Minas Gerais, Belo Horizonte, 2005.

PEREIRA, D. B. C. et al. Físico-química do leite e derivados: Métodos analíticos. Juiz de Fora: Oficina de Impressão Gráfica e Editora Ltda., 2001, 190 p.

PINTO, M. S. Diagnóstico socioeconômico, cultural e avaliação dos parâmetros físico-químicos e microbiológicos do Queijo Minas Artesanal do Serro. 2004. $134 \mathrm{f}$ Dissertação (Mestrado em Ciência e Tecnologia de Alimentos) - Universidade Federal de Viçosa, Viçosa, 2004.

PINTO, M. S. et al. The effects of nisin on Staphylococcus aureus count and the physicochemical properties of Traditional Minas Serro cheese. International Dairy Journal, v. 21, p. 90-96, 2011.

PINTO, M. S. et al. Queijo Minas Artesanal da região do Serro: Avaliação de Staphylococcusaureus e suas enteroxinas. Revista do Instituto de Laticínios Cândido Tostes, v. 59, n. 336, p. 82-86, 2004.

POMBO, A. F. W.; LIMA, A. Extensão e profundidade de proteólise em queijo Minas Frescal. Revista do Instituto de Laticínios Cândido Tostes, v. 44, n. 261/266, p. 50-55, 1989.

RESENDE, M. F. S. Queijo Minas artesanal 
da Serra da Canastra: influência da altitude e do nível de cadastramento das queijarias nas características físico-químicas e microbiológicas. 2010. 72 p. Dissertação (Mestrado em Ciência Animal) - Escola de Veterinária da Universidade Federal de Minas Gerais, Belo Horizonte, 2010.

SILVA. J. G. Características físicas, físico-químicas e sensoriais do queijo Minas artesanal da Canastra. 2007. 198 p. Dissertação (Mestrado em Ciência dos Alimentos) - Universidade Federal de Lavras, Lavras, 2007.

SOBRAL, D. Efeito da nisina na sobre Staphylococcus aureus e características físico-químicas, maturação, perfil de textura e cor do queijo minas artesanal da região de Araxá. 2012. 100p. Tese (Doutorado em Ciência e Tecnologia de Alimentos) - Universidade Federal de Viçosa, Viçosa, 2012.

TEODORO, V. A. M. Efeito da nisina na multiplicação de Staphylococcus aureus e nas características físico-químicas, reológicas e microbiológicas do queijo Minas artesanal da Serra da Canastra - MG. 2012. 138p. Tese (Doutorado em Ciência e Tecnologia de Alimentos) - Universidade Federal de Viçosa, Viçosa, 2012.

VARGAS, O. L. et al. Características de origens para queijos naturais de Minas Gerais: municípios do Serro e São Roque de Minas. Revista do Instituto de Laticínios Cândido Tostes, v. 53, n. 301-303, p. 19-49, 1998. 